\title{
Bireylerin Kardiyovasküler Sağlık Durumlarının ve İyilik Hallerinin Belirlenmesi
}

\author{
Hilal Uysal, $\oplus$ Hanım Büşra Oruçoğlu \\ İstanbul Üniversitesi, Cerrahpaşa Florence Nightingale Hemşirelik Fakültesi, İç Hastalıkları Hemşireliği Anabilim Dalı, İstanbul
}

\begin{abstract}
Özet
Amaç: Çalışma, 20 yaş ve üzeri bireylerin kardiyovasküler sağlık durumlarının, iyilik hallerinin ve iyilik halinin kardiyovasküler sağlık durumuna etkisinin belirlenmesi amacıyla planlandı ve gerçekleştirildi.

Yöntemler: Araştırma, İstanbul'da bir üniversitede Nisan-Mayıs 2019 tarihleri arasında Marmara bölgesinde yaşayan, araştırmanın amacı ve araştırmadan beklentiler hakkında bilgilendirme yapılan ve araştırmaya katılmaya istekli olan 20 yaş ve üzeri 248 birey ile gerçekleştirildi. Çalışmada veri toplama araçları olarak, bireylerin sosyodemografik özelliklerini ölçmeye yönelik oluşturulmuş anket formu, Amerikan Kalp Birliği Life's Simple 7 kardiyovasküler sağlık ölçüm anketi, Günlük Besin Tüketim Kayıt Formu ve İyilik Hali Ölçeği kullanıldı.

Bulgular: Çalışmaya katılan bireylerin \%80.2'si kadın, yaş ortalaması 20.935 1.845 , çoğunluğunun normal beden kitle indeksine sahip olduğu tespit edildi. Çalışmaya katılan bireylerin kardiyovasküler sağlık durumlarının yüksek düzeyde (8.479 \pm 1.944$)$ olduğu, kadınların erkeklerden daha yüksek ideal kardiyovasküler sağlık durumuna sahip olduğu bulundu. Çalışmada ideal kardiyovasküler sağlık durumuna göre kadınların kan basıncı $(p=0.005)$, beden kitle indeksleri $(p=0.046)$ ve sigara içme oranları $(p=0.000)$ erkeklere göre daha düşük, dolayısı ile kardiyovasküler sağlık durumu pu-

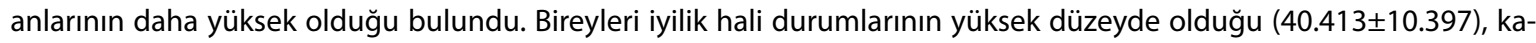
dınların çoğunluğunun erkeklerden daha yüksek iyilik düzeyine sahip olduğu bulundu $(p<0.05)$. Bireylerin iyilik halinin kardiyovasküler sağlık üzerine etkisini açıklamak için anlamlı düzeyde olmadığı bulundu.

Sonuç: Sonuç olarak, çalışmaya katılan bireylerin yarısının ideal kardiyovasküler sağlık düzeyine sahip olduğu, bireylerin kardiyovasküler sağlık durumu puan ortalamalarının yüksek düzeyde olduğu bulundu. Bireylerin iyilik halinin kardiyovasküler sağlık üzerine etkisinin olmadığı saptandı.
\end{abstract}

Anahtar sözcükler: Besin; iyilik hali; kalp; kardiyovasküler hastalık; sağlık; sağlık davranışları.

\section{Determination of Cardiovascular Health Status and Well-Being of Individuals}

\footnotetext{
Abstract

Objective: The study was planned and carried out to determine the effects of cardiovascular health status, well-being and well-being on cardiovascular health status of individuals aged 20 years and older.

Methods: The study was conducted with 248 individuals over 20 years of age who were living in the Marmara region between April-May 2019 at a university in Istanbul, who were informed about the purpose and expectations of the study and were willing to participate in the study. Data were collected by using a questionnaire for measuring the sociodemographic characteristics of individuals, American Heart Association Life's Simple 7 cardiovascular health questionnaire, Daily Food Consumption Record Form and Goodness Scale.
}

İletişim (Correspondence): Dr. Hilal Uysal. İstanbul Üniversitesi, Cerrahpaşa Florence Nightingale Hemşirelik Fakültesi, İ̧ Hastalıkları Hemşireliği Anabilim Dalı, Abide-i Hürriyet Cad, Şişli, İstanbul, Turkey

Telefon (Phone): +90 5358170616 E-Posta (E-mail): hilaluysal@gmail.com

Başvuru Tarihi (Submitted Date): 20.08.2019 Kabul Tarihi (Accepted Date): 10.09.2019

oCopyright 2019 by Turkish Society of Cardiology - Available online at www.anatoljcardiol.com 
Results: It was found that $80.2 \%$ of the participants were female, mean age was $20.935 \pm 1.845$, and the majority had normal body mass index. The cardiovascular health status of the participants was found to be high (8.479 \pm 1.944$)$ and females had higher ideal cardiovascular health status than men. In the study, blood pressure $(p=0.005)$, body mass index $(p=0.046)$ and smoking ( $p=0.000)$ were higher in women than men in terms of ideal cardiovascular health status. The well-being status of individuals was found to be high (40.413 \pm 10.397$)$, and the majority of women had higher levels of well-being than men $(p<0.05)$. It was found that the well-being of individuals was not significant to explain the effect of cardiovascular health.

Conclusion: As a result, it was found that half of the individuals participating in the study had an ideal cardiovascular health level and the mean scores of the cardiovascular health status of the individuals were high. It was found that the well-being of the individuals had no effect on cardiovascular health.

Keywords: Cardiovascular disease; food; heart; health behaviors; well-being.

Cite this article as: Uysal H, Oruçoğlu HB. Nursing Care and Education of Pulmonary Arterial Hypertension Patients Receiving Continuous Intravenous Prostacyclin Treatment. Turk J Cardiovasc Nurs 2019;10(22):67-77.

Y aşam süresi perspektifinden bakıldığında, çocukluk, ergenlik ve erken yetişkinlik döneminde kardiyovasküler (KV) sağlığın yüksek oranda iyi olmasının yetişkinlikte de aynı ideal kardiyovasküler sağlık (KVS) oranına sahip olacaklarının muhtemel olduğu düşünülmektedir. Evlerde, okullarda, okul sonrası ortamlarda ve topluluklarda, çocukların ve gençlerin zaman geçirdiği yerlerde ideal düzeyde KV sağlığın sağlanması ve/veya sürdürülmesi için fırsatlar oluşturulmalıdır. İdeal olan, tüm çocuklar ve gençlerin sigara kullanmadığı, sağlıklı yiyeceklerin tüketildiği evlerde yaşaması ve aile düzenine sahip olması, birlikte fiziksel aktivite yapmasıdır. Bunlara ek olarak, sigara içmeyen ve sağlıklı gıda seçenekleri sunan (otomatlar ve kafeteryalar vb.), fiziksel aktivite yapma olanakları sağlayan, obezite, kan basıncı, kolesterol ve kan şekeri gibi biyometrik taramalar sunan bir iş yeri, ideal düzeyde KV sağlığı elde etmek için çabalayan bireyi destekleyebilir. Amerikan kalp birliği (AHA) bu koşulların sağlanmasının daha iyi KV sağlık düzeyine ulaşılması için şart olduğunu, kardiyovasküler hastalık (KVH) ve erken ölüm riskini önlediğini belirtmektedir. ${ }^{[1]}$ Sosyal hayatın hızlı ilerlemesinin yanında çalışan sayısının artması, iş yoğunluğu, evde yemek hazırlamak için yeterli zaman ve enerjinin olmaması gibi faktörler nedeniyle bireyler ev dışında yemek yeme alışkanlığı kazanmaktadır. İş yaşamı dışındaki vakitleri etkin kullanmak için bireyler yemek hazırlamak için zaman harcamak istememektedirler. Bu nedenle hızlı yemek kavramı ortaya çıkmıştır. Yapılan bir çalışmada üniversite öğrencileri arasında en çok tercih edilen hızlı yemek alışkanlıkları arasında \%25.7 oranında hamburger, \%26.7 oranında çiğ köfte, \%44.6 oranında lahmacun, \%40.3 oranında döner, \%15.3 oranında pizza yer almaktadır. Öğrencilerin bu gıdaları öncelikle tercih etmelerinin nedenleri arasında en yüksek payı "ürünün her an hazır bulunması" almaktadır. Tercihteki diğer önemli bir faktör de bu gıdaların ucuz olmasıdır. ${ }^{[2]}$

Kardiyovasküler hastalıklar küresel boyutta mortaliteyi arttıran en önemli faktörlerden birisidir. 2013 Küresel Hasta- lık Yükü Çalışması, KV ölümlerin dünyadaki tüm ölümlerin neredeyse üçte birini oluşturduğunu göstermektedir.[1] Dünya Sağlık Örgütü (DSÖ)'ne göre her yıl 17.5 milyon insan $\mathrm{KVH}$ 'dan ölmekte ve dünyadaki tüm ölümlerin \%31'ini temsil etmektedir. Son zamanlarda birçok gelişmiş ülkede KVH mortalite oranlarındaki düşüşe rağmen, kardiyovasküler hastalıklar gelişmekte olan ülkelerde en önemli ölüm nedeni olmaya devam etmektedir. Kardiyovasküler sağlığı (KVS) geliştirmek için herhangi bir girişim yapılmazsa ve mevcut eğilimler devam ederse, DSÖ 2020'ye kadar dünya genelinde \%25'den daha fazla boyutta sağlıklı yaşam yıllarının KV hastalıklarla kaybedileceğini tahmin etmektedir. ${ }^{[3]}$ Koroner kalp hastalığı (KKH) risk faktörlerinin prevalansının yüksek olmasına ve bu yaş grubundaki erken ateroskleroz belirtilerine rağmen 18-24 yaş arasındaki genç erişkinlerinde koroner kalp hastalığı riski hafife alınmaktadır. KKH, KVH ölümlerinin \%50'sini oluşturmaktadır ve genç erişkinlerde önde gelen ölüm nedenlerinden birisidir. Genç erişkinlerin yarısından fazlası en az bir KKH risk faktörüne sahiptir ve bu durum yaşam süresince kalp hastalığı riskini büyük ölçüde artırır. Birçok KKH risk faktörü ergenlikte ortaya çıktığı ve erişkinlikte devam ettiği için, AHA'nın 2020 stratejik etki hedeflerinde Ulusal Kalp Akciğer ve Kan Enstitüsü (The National Heart, Lung and Blood Institute-NHLB), çocuklarda ve ergenlerde KV sağlık ve risk azaltılması için 2012 entegre kılavuzlar uzman panelinde çocukluk ve ergenlikte başlayan primer önlemenin altını çizmektedir. AHA'nın 20 yaşından büyük tüm yetişkinlerin taranmasına yönelik önerilerine rağmen, kadınların <\%50 ve erkeklerin <\%40' KKH riski açısından taranmaktadır. Ayrıca, genç yetişkinlerin çoğunluğu risklerinin farkında değildir. İlke olarak risk faktörü gelişiminden kaçınmak için birincil önleme stratejileri uygulanıncaya kadar, bu yaş grubunda daha iyi tarama, risk değerlendirmesi, yönetimi ve eğitime ihtiyaç vardır. Erken tanı ve girişimler önemlidir. Çünkü KVH'ların \%80'i beslenme şekli ve yaşam şekli değişiklikleri ile önlenebilmektedir. ${ }^{[4]}$

Amerikan kalp birliği 2020 etki hedeflerinde, Amerika Bir- 
leşik Devletleri (ABD)'nde KV sağlığı iyileştirmeyi ve KV hastalık ve inmeden kaynaklanan ölümleri azaltmayı planlamıştır. Bu arada AHA, 2020 hedeflerine ulaşmayı sağlamak amacıyla, KV sağlık durumunu tanımlamak ve izlemek için, ideal KV sağlığa ulaşmada bir yol olan, "Life's Simple 7 (LS7)" adlı yedi değiştirilebilir ölçüm belirlemiştir. Life's Simple 7, değiştirilebilir dört davranış (sigara içmemek, sağlıklı kilo vermek, sağlıklı yemek ve fiziksel olarak aktif olmak) ve üç biyometrik önlemi (kan basıncı kan şekeri ve kolesterol) içermektedir. AHA, LS7 puanı ne kadar yüksek tutulursa bireylerin daha sağlıklı ve daha uzun ömürlü olacağını ve kardiyovasküler koruma sağlayacağını belirtmektedir. ${ }^{[1,5]} \mathrm{Bu}$ nedenle KV sağlığın teşviki ve KV hastalığı önleme çabaları için her yaştan ve her bireyin yaşam boyunca sağlıklı alışkanlıklar kazandırılması ve bunların sürdürülmesi yönünde teşvik edilmesi önemlidir. ${ }^{[1]}$

Prospektif çalışmalar göstermiştir ki, daha genç yaşta ideal KV sağlık ölçümlerinin olması, tüm nedenler ve bağlı ölüm riskinin, ${ }^{[6]}$ en düşük fonksiyonel sakatlık oranının ${ }^{[7]}$ ve daha düşük yaşta düşük sağlık maliyetleriyle ilişkili olduğunu göstermiştir. ${ }^{[5]}$ Son zamanlarda yapılan birkaç araştırmada Life's Simple 7'nin KVH mortalitesinin, insidansının ve varlığının azaltılması üzerindeki etkileri gösterilmiştir. ${ }^{[8-11]}$ Ayrıca farklı popülasyonlardaki KV sağlık durumu hakkında da birkaç rapor bulunmaktadır. [12-15]

Bu kanıtlar sonucunda sağlık çalışanları için KV sağlığın 7 bileşenini ele alma önerileri ortaya çıkmıştır. Sağlık profesyonellerinin halk sağlığı ve klinik bakımdaki tavsiyelerinin ve çabalarının, yaşamlarının başında iyi veya ideal KVS elde edilmesini ve yüksek KV sağlığın mümkün olduğunca uzun süre korunmasını teşvik etmesi gerektiği açıktır. ${ }^{[1]}$

Sağlıklı beslenme, düzenli fiziksel aktivite, etkin stres yönetimi, sigara kullanmama, hijyenik önlemler ve kendi sağlık sorumluluğunu alabilme olarak tanımlanan sağlıklı yaşam biçimi davranışları, kardiyovasküler hastalık riskini düşürmektedir. ${ }^{[16]}$ Sağlığın teşviki ve geliştirilmesi için sigara bırakma ve sigara bırakma konusundaki yoksunluğun önemi dikkate alındığında, sigara kullanımı hem sağlık faktörlerinde hem de sağlık davranışlarında listelenmiştir. Epidemiyolojik kanıtlar, ideal KV sağlığın, düşük KVH riski, daha düşük KVH mortalite oranları ve tüm nedenlere bağlı düşük ölüm oranı, hastalıksız sağ kalım, daha iyi yaşam kalitesi ve daha düşük sağlık maliyetleri ile ilişkili olduğunu göstermektedir. ${ }^{[17]}$

\section{Gereç ve Yöntem}

Araştırmanın amacı ve türü: Çalışma 20 yaş ve üzeri bireylerin kardiyovasküler sağlık durumlarının, iyilik hallerinin ve iyilik halinin kardiyovasküler sağlık durumuna etkisinin belirlenmesi amacıyla tanımlayıcı bir çalışma olarak planlandı ve uygulandı.

\section{Araştırmanın Evren ve Örneklemi:}

Araştırma, Nisan-Mayıs 2019 tarihleri arasında Marmara bölgesinde yaşayan araştırmanın amacı ve araştırmadan beklentiler hakkında bilgilendirme yapılan ve araştırmaya katılmaya istekli olan 20 yaş ve üzeri 248 birey ile gerçekleştirildi. Ayrıca çalışmada 20 yaş ve üzeri bireylerin iyilik halinin ve KV sağlık durumlarının nasıl olduğu ve bireylerin iyilik hallerinin KV sağlıklarının üzerine etkisinin ne düzeyde olduğu sorularına cevap arandı.

Araştırmaya katılmaya istekli olan 20 yaş ve üzeri, Türkçe okuma yazma bilen, araştırmacı ile işbirliği yapabilen bireyler araştırmaya dahil edildiler. Araştırmaya katılmaya istekli olmayan, bilişsel işlev bozukluğu olan ve soruları algılamasını, iletişim kurmasını etkileyecek düzeyde sağılı sorunu olanlar çalışmaya dahil edilmediler. Çalışmada \%95 güven aralığı ve $\% 5$ hata payı ile toplam evren sayısı 280 birey olup araştırmadaki örneklem sayısı 163 olarak hesaplanmıştır. Çalışmada ise 225 birey ile görüşme sağlanmıştır. Ancak günlük besin tüketim kayıt formunun eksik doldurduğu tespit edilen 7 bireyin verileri çalışmaya dahil edilmedi. Bu nedenle çalışmaya toplam 248 birey dahil edildi. Hesaplanan örneklem hesabından daha yüksek örneklem ile görüşme sağlandı.

\section{Veri Toplama Araçları}

Çalışmada veri toplama araçları olarak, bireylerin sosyodemografik özelliklerini ölçmeye yönelik oluşturulmuş anket formu (7 madde), AHA Life's Simple 7 (LS7) kardiyovasküler sağlık ölçüm anketi (7 madde), Günlük Besin Tüketim Kayıt Formu ve İyilik Hali Ölçeği (8 madde) kullanıldı. Kullanılacak veri toplama araçları madde sayısı 22'dir. Araştırma için kullanılan veri toplama formları, yüz yüze görüşme yöntemiyle araştırmacılar tarafından gerçekleştirildi. Anket uygulaması yaklaşık 10 dakika sürdü.

-Life's Simple 7 ölçüm aracı: Amerikan kalp birliği, kalp sağlığının en önemli yedi belirleyicisi ve aynı zamanda ideal kardiyovasküler sağlığa ulaşmak için bir yol olan "Life's Simple 7 (LS7)"yi geliştirmiştir. LS7, değiştirilebilir dört davranış (sigara içmemek, sağlıklı kilo vermek, sağlıklı yürümek ve fiziksel olarak aktif olmak ) ve üç biyometrik önlemi (kan basıncı, kolesterol ve kan şekeri) içerir. Bu 7 faktör üç kategoriye ayrılır; ideal, orta ve kötü. Yedi ölçümün tümü için ideal seviyeye sahip bireylerin ideal kardiyovasküler sağlığa sahip olduğu düşünülmektedir. Araştırmalar, Life's Simple 7 önlemlerinin üç ile dördünü karşılayan kişilerin kalp kaynaklı ölüm risklerini yarıdan fazla azalttığını göstermiştir. ${ }^{[1]}$

Life's Simple 7'de diyet fiziksel aktivite, sigara içme, beden kitle indeksi, kan basıncı, kolesterol ve kan şekeri dahil kar- 
diyovasküler sağlık göstergelerinin AHA kriterlerine göre ölçülüp, kategorik olarak ideal, orta veya zayıf olarak kodlanması ile değerlendirme yapılmaktadır.

\section{AHA'nın ideal KVS tanımları:}

1. İdeal sigara içme durumu; 1 yıldan daha önce hiç sigara içmemesi veya sigarayı bırakmış olmadır.

2. İdeal diyet (Beslenme durumu)

1.Günde $\geq 4$ porsiyon sebze meyve tüketmesi,

2. Haftada $\geq 200$ gr balık tüketmesi ( $\geq 2$ porsiyon/hafta)

$3.10 \mathrm{gr}$. karbonhidrat için $<1 \mathrm{gr}$ lif oranı yüksek şeklinde lif bakımından zengin kepekli tahıllı ürünleri tüketilmesi ( $\geq 3$ porsiyon/gün),

\section{Sodyum günde $<1500 \mathrm{mg}$}

5. Şekerli tatlandırılmış yiyecek ve içecekler = Haftada $\leq 450$ kkaloriden az tüketilecektir. (bunu belirlemek için hastalara haftalık besin tüketim kayıt formu verilecek).

3. İdeal fiziksel aktivite, hastalığa ve hekim öncesine uygun olarak, ter atmaya yetecek kadar yoğun fiziksel aktivite için haftada $\geq 4$ gün/hafta fiziksel aktivite yapmasıdır. ("Haftada kaç kez ter atmaya yetecek kadar orta ve yoğun fiziksel aktivite yapıyorsunuz?" şeklinde soru sorulacak)

4. İdeal beden kitle indeksi (BKi); $25 \mathrm{~kg} / \mathrm{m}^{2}$ olarak tanımlanacaktır.

5. İdeal Kan Basıncı (KB); 2 ölçümün ortalamasından sistolik kan basıncı (SKB) $<120 \mathrm{mmHg}$, diyastolik kan basıncı (DKB) $<80 \mathrm{mmHg}$ olarak tanımlanacak; Antihipertansif tedavisi alanlar kayıt edilecektir.

6. İdeal total kolesterol $<200 \mathrm{mg} / \mathrm{dL}$ olarak tanımlanacak, lipit düşürücü tedavi alanlar kayıt edilecektir.

7. İdeal Açlık Kan Şeker (AKŞ); $<100 \mathrm{mg} / \mathrm{dL}$ olarak tanımlanacak, insülin veya oral hipoglisemik ilaçla tedavi alanlar kayıt edilecektir.

İdeal sağlığın aksine, kötü sağlık, sigara içiyor olmak, 5 diyet önerisinden en az birini yapmak, fiziksel aktivite yapmamak ve yüksek BKi $\left(30 \mathrm{~kg} / \mathrm{m}^{2}\right)$, yüksek kan basıncı (SKB $\geq 140$ $\mathrm{mmHg}, \mathrm{DKB} \geq 90 \mathrm{mmHg}$ ), yüksek total kolesterol ( $\geq 240 \mathrm{mg} /$ $\mathrm{dL}$ ) ve yüksek AKŞ olması ( $\geq 126 \mathrm{mg} / \mathrm{dL}$ ) ile karakterizedir.

Her bileşen için ideal KVS için 2 puan, orta KVS için 1 puan ve düşük KVS için 0 puan vererek Life's Simple 7 toplam puanı hesaplanmaktadır. Her birey için LS7 toplam puanı 0-14 puan arasında KV sağlık durumu hesaplanmaktadır. Toplam puan "0" (en kötü KVS) puanı ile "14" (en iyi KVS) puanı arasında toplam puan elde etmek için 7 bileşenin puanları toplanacak. 0-6 puan arası düşük KV sağlık; 7-8 arası orta KV sağlık; 9-14 arası ideal KV sağlık durumu olarak puanlanmaktadır (Tablo 1). ${ }^{[18]}$
-Günlük Besin Tüketim Kayıt Formu: Günlük besin tüketim kayıt formu kullanılarak bireylerin 24 saatlik besin tüketim durumları sorgulandı. Bireyin forma yazdığı günlük tükettiği gıdalar günlük tüketilen porsiyonlara dönüştürüldü. Her bir gıda hangi gruptaysa ona göre tablodan puanlaması yapıldı.

-lyilik Hali Ölçeği (iHÖ): İyilik Hali Ölçe, Diener ve ark.(2009) (Cronbach alfa 0.87) tarafından geliştirilmiştir. ${ }^{[19]}$ Türkçe geçerlik ve güvenirliği Fidan ve Usta (2013) (Cronbach alfa 0.83) tarafından yapılmıştır. Ölçek tek boyut altında toplanan, 8 maddeli, geçerli ve güvenilir bir araç olarak gösterilmektedir. Bu ölçek katılımcıların iyilik haline ilişkin algılarını değerlendiren ve bireyin kendisi hakkında bilgi vermesine dayanan (self-report) bir ölçme aracıdır. Katılımcılardan ölçek maddelerine 1-kesinlikle katılmıyorum yanıtından 7-tamamen katılıyorum yanıtına kadar değişkenlik gösteren 7'li Likert tipi bir derecelendirmede görüş bildirmeleri beklenmektedir. Ölçekte yer alan tüm maddelerin puanları toplanarak toplam bir iyilik hali puanı elde edilebilmektedir. Ölçekten elde edilebilecek en yüksek puan 56, en düşük puan ise 8 (8-24 puan düşük iyilik hali, 25-39 puan orta iyilik hali, 40-56 puan yüksek iyilik hali) olarak hesaplanmaktadır. Ölçekte ters puanlanan madde bulunmamaktadır. Ölçekten alınan yüksek puanlar bireyin iyilik hali düzeyinin yüksek olduğunu göstermektedir. Bizim çalışmamızda da ölçeğin Cronbach alfa değeri 0.926 olarak bulundu. Geçerlik ve güvenirlik çalışmalarından ${ }^{[19,20]}$ elde edilen bulgulardan daha yüksek bir değer elde edildi. IHÖ'nün Türkçe formunun geçerli ve güvenilir bir ölçme aracı olarak kullanılabileceğini göstermektedir. ${ }^{[20]}$

\section{Araştırmanın Etik Yönü}

Araştırmanın uygulanabilmesi için araştırmada kullanılacak olan veri toplama araçları geliştirenlerden ve etik kuruldan (2019) gerekli izinler alındı. Araştırmaya katılmaya istekli olan bireylere Helsinki Bildirgesi doğrultusunda araştırmanın amacı ve beklentiler hakkında bilgi verildi ve gönüllü katılım sağlanarak sözlü ve yazııı onamlar alındı.

\section{Verilerin Değerlendirilmesi}

Çalışmanın istatistikleri IBM SPSS Windows 21.0 paket programı (IBM Corp. Armonk, N.Y. USA) ile yapıldı. Araştırmanın istatistiksel değerlendirilmesinde, nitel ve sayısal değişkenler için sayısal ve yüzdelik dağılımlar kullanıldı. İki veya daha fazla değişken arasındaki farklılıkların değerlendirilmesi için istatistiksel testler (iki ortalama arasındaki farkın önemlilik testi, varyans analizi) ve korelasyon testi yapıldı. İstatistiksel anlamlılık değeri $p<0.05$ olarak kabul edildi. 
Tablo 1. AHA'nın 2020 hedeflerinde 20 yaş ve üzeri yetişkin bireyler için düşük, orta ve ideal kardiyovasküler sağlık tanımları

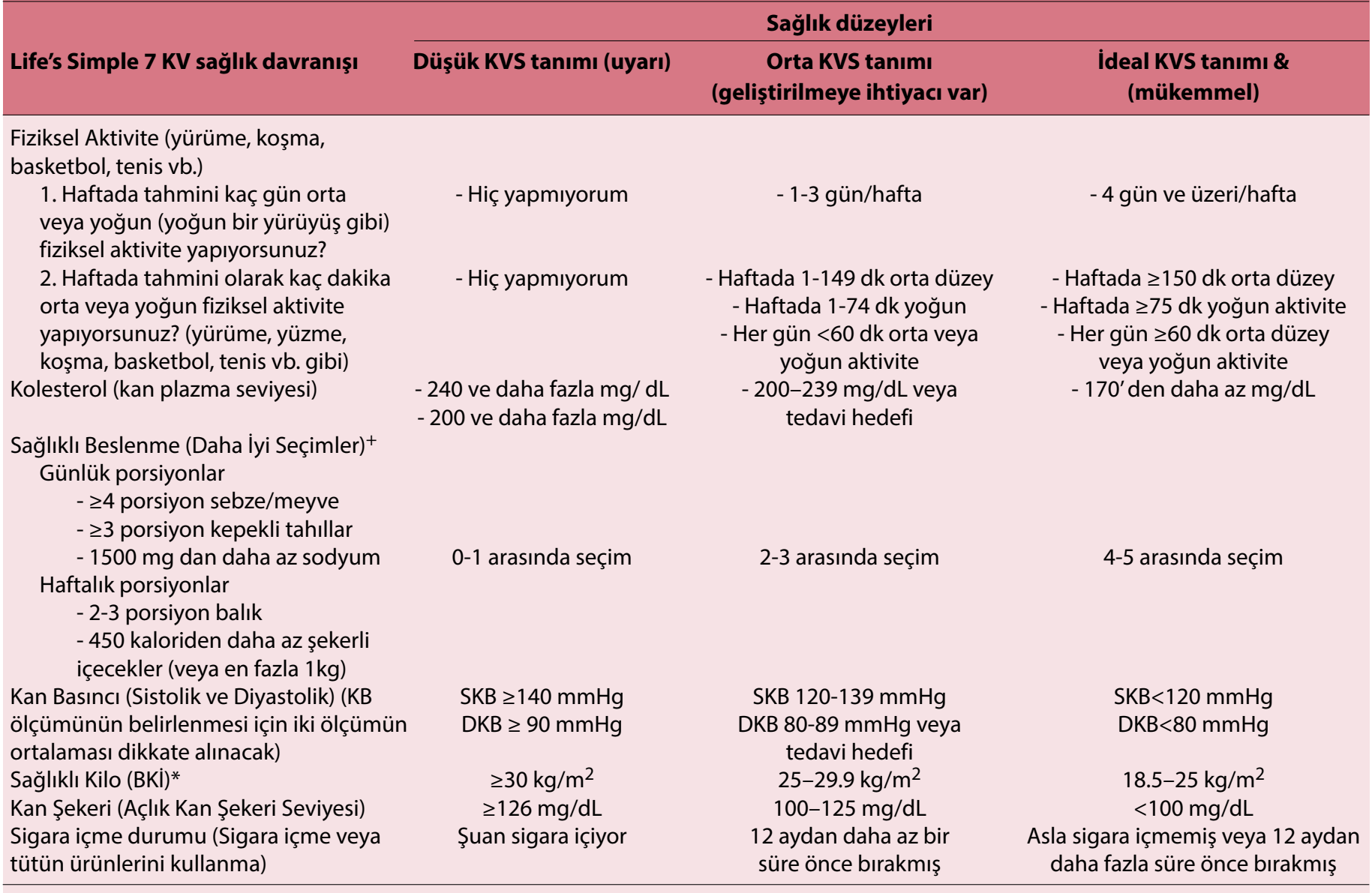

\& İstenen ideal oranlar; +Hipertansiyonu durdurmak için diyet yaklaşımları (DASH) tipi beslenme düzeni ile uyumlu, $\geq 4.5$ kase/gün sebze meyve; $\geq 2$ porsiyon/ hafta balık; $\geq 3$ porsiyon/gün kepekli tahıllar ve en fazla $36 \mathrm{oz}(1 \mathrm{~kg}) /$ haftada şekerli içecekler ve günde $1500 \mathrm{mg}$ sodyum. *Uygun enerji dengesini temsil eder (yani normal vücut ağırığını korumak için uygun diyet miktarı ve fiziksel aktivite) boy ve kilo ölçümü sonrası $\mathrm{kg} / \mathrm{m}^{2}$ cinsinden BKi hesaplaması yapılır.

\section{Bulgular}

Çalışmaya katılan bireylerin \%80.2'si kadın, yaş ortalaması $20.935 \pm 1.845$, çoğunluğunun (\%80.2) normal beden kitle indeksi (BKi)'ne sahip olduğu tespit edildi (Tablo 2).

Çalışmada ideal kardiyovasküler sağlık durumuna göre kadınların kan basıncı $(p=0.005)$, beden kitle indeksleri $(p=0.046)$ ve sigara içme oranları $(p=0.000)$ erkeklere göre daha düşük, dolayısı ile kardiyovasküler sağlık durumu puanlarının daha yüksek olduğu bulundu (Tablo 3).

Çalışmada bireylerin iyilik hali değerlendirildiğinde, "amaçlı ve anlamlı bir yaşam sürme", "sosyal ilişkilerinin destekleyici olması", "kendisi için önemli olan faaliyetlerde yetkin ve yetenekli olma", "insanların saygı duyması" konularına kadınların erkeklere göre daha yüksek oranda katılım sağladığı ve anlamlı düzeyde olduğu bulundu $(p<0.05)$ (Tablo 4).

Çalışmaya katılan bireylerin LS7'ye göre KV sağlık durumları değerlendirildiğinde \%50.4'ünün ideal, \%34.3'ünün orta,

\begin{tabular}{|c|c|}
\hline & n (\%) \\
\hline Yaş (Mean \pm SS) & $20.935 \pm 1.845$ \\
\hline \multicolumn{2}{|l|}{ Cinsiyet } \\
\hline Kadın & $199(80.2)$ \\
\hline Erkek & $49(19.8)$ \\
\hline \multicolumn{2}{|l|}{ Ailede kalp hastalığı } \\
\hline Yok & $171(69.0)$ \\
\hline Anne & $15(6.0)$ \\
\hline Baba & $16(6.5)$ \\
\hline Diğer & $46(18.5)$ \\
\hline Antihipertansif ilaç kullanmıyor & $248(100)$ \\
\hline Kolesterol ilacı kullanmıyor & $248(100)$ \\
\hline \multicolumn{2}{|c|}{ İnsülin veya oral diyabet ilacı kullanma } \\
\hline Evet & $1(0.4)$ \\
\hline Hayır & $247(99.6)$ \\
\hline \multirow[t]{2}{*}{ BKi $\left(\mathrm{kg} / \mathrm{m}^{2}\right)+($ Mean $\pm S S)$} & $21.922 \pm 3.165$ \\
\hline & Min: 15.67 Max: 34.48 \\
\hline 30 (obez) & $22(8.9)$ \\
\hline 25-29.9 (fazla kilolu) & $27(10.9)$ \\
\hline $18.5-25$ (normal) & $199(80.2)$ \\
\hline
\end{tabular}

${ }^{+}$BKI: Beden Kitle İndeksi. 


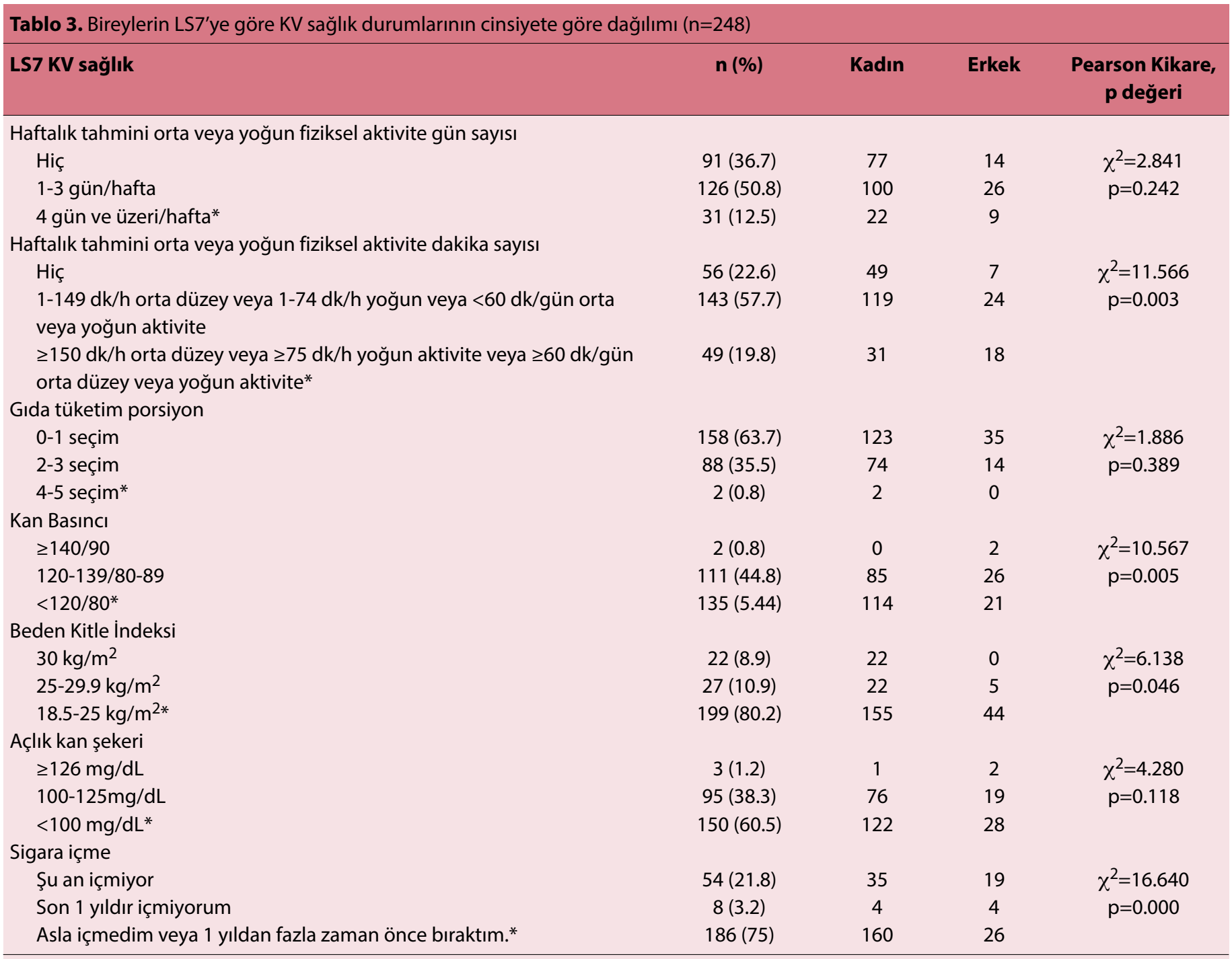

*ideal KV sağlık durumu.

\%15.3'ünün düşük KV sağlık düzeyine sahip olduğu bulundu. Kadınların KV sağlık düzeyinin erkeklere göre daha yüksek olduğu bulunurken aralarında anlamalı fark bulunmadı ( $p=0.474$ ) (Tablo 5). Çalışmaya katılan bireylerin KVS durumlarının yüksek düzeyde (8.479 \pm 1.944$)$ olduğu, kadınların erkeklerden daha yüksek ideal KVS durumuna sahip olduğu bulundu ( $p=0.652$ ) (Tablo 5).

BKi $30 \mathrm{~kg} / \mathrm{m}^{2}$ olan bireylerin yüksek iyilik haline sahip olduğu, bununla birlikte normal BKi'ye sahip olanların yüksek KV sağlığa sahip oldukları bulundu. Bireylerin BKi değerleri normal olanların LS7'ye göre KV sağlık durumlarının ideal düzeyde olduğu, obez olanların düşük, fazla kilolu olanların ise orta düzeyde oldukları tespit edildi $(p=0.000)$. İdeal BKi'ne sahip bireylerin çoğunluğunun yüksek iyilik haline sahip oldukları bulundu. Ancak aralarında anlamlı fark bulunmadı ( $p=0.464$ ) (Tablo 5). Bireyleri iyilik hali durumları- nın yüksek düzeyde olduğu (40.413 \pm 10.397$)$, kadınların çoğunluğunun erkeklerden daha yüksek iyilik düzeyine sahip olduğu bulundu $(p<0.05)$ (Tablo 5).

Çalışmada bireylerin LS7 KV sağlık durumu ile iyilik halleri arasında anlamlı bir ilişki bulunmadı ( $r=0.079 . p=0.218)$. Regresyon analizi kullanılarak iyilik hali değiştiğinde KV sağlığın nasıl değiştiği araştıııldı. Analizde, bireylerin iyilik halinin KV sağlık üzerine etkisini açıklamak için anlamlı bulunmadı $(\mathrm{t}=1.235 \mathrm{p}=0.218)$.

Çalışmaya katılan bireyler arasında haftada 4 gün ve üzeri (ideal) ve $\geq 150 \mathrm{dk} / \mathrm{h}$ orta düzey veya $\geq 75 \mathrm{dk} / \mathrm{h}$ yoğun aktivite veya $\geq 60 \mathrm{dk} /$ gün orta düzey veya yoğun fiziksel aktivite (ideal düzey) yapanların KV sağlık düzeylerinin daha yüksek olduğu, haftada 1-3 gün ve 1-149 dk/h orta düzey veya $1-74 \mathrm{dk} / \mathrm{h}$ yoğun veya $<60 \mathrm{dk} /$ gün orta veya yoğun fiziksel aktivite (orta düzey) yapanların iyilik hallerinin daha yüksek 


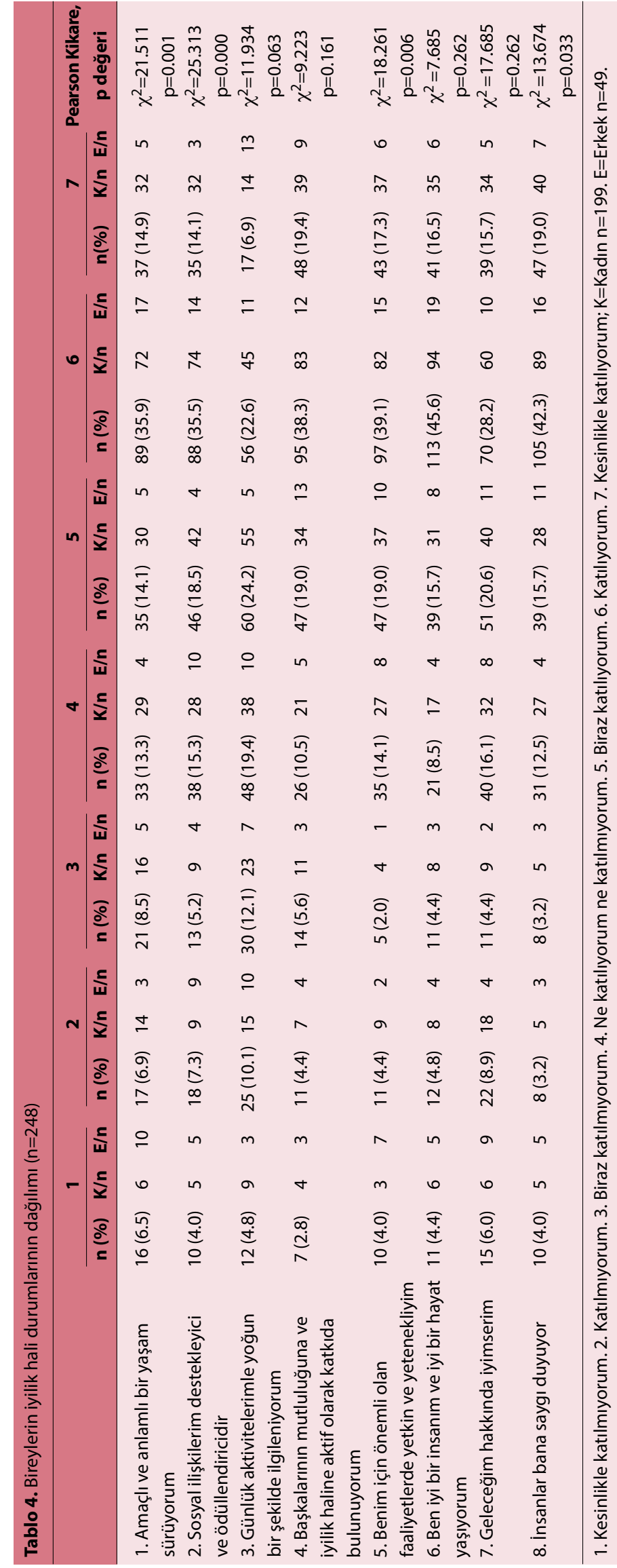

olduğu bulundu (Tablo 6).

Çalışmada 2-3 tane sağlıklı gıda tüketim seçimi olanların KV sağlık düzeyinin daha yüksek olduğu, 4-5 tane seçim yapanların ise iyilik halinin en yüksek düzeyde olduğu bulundu. BKi normal olanların KV sağlık düzeyinin yüksek olduğu görülürken, obez bireylerin iyilik hali düzeylerinin yüksek olduğu bulundu. AKŞ oranı $<100 \mathrm{mg} / \mathrm{dL}$ olanların ve asla sigara içmeyenlerin veya bir yıldan fazla zaman önce bırakanların hem KV sağlık durumunun hem de iyilik hallerinin yüksek olduğu bulundu (Tablo 6).

\section{Tartışma}

2010 yılında AHA tarafından, KV hastalıklardan kaynaklanan yaş ayarlı mortaliteyi \%20 azaltmak ve KV sağlığı \%20 arttırmak için 2020 stratejik etki hedefleri tanımlanmıştır. Bunun için de $7 \mathrm{KV}$ sağlık ve yaşam şekli bileşenlerinin ideal seviyeleri belirlenmiş ve birinci korunma hedefleri olarak açıklanmıştır. ${ }^{[21]}$ Bu süreden sonra çalışmalarda ideal KV sağlık puanı kullanılmış ve yüksek puanların tüm nedenlere bağlı ölüm riski, klinik ve subklinik KV hastalık riski ile ilişkili olduğu sonucu ortaya çıkmıştır. [22, 23]

KV sağlığın iyileştirilmesi için "asla asla geç değildir" ilkesinden yola çıkılarak, LS7 puanının yüksek tutulması önemli fayda sağlayacaktır. Sigara içmemek, önerilen aktivite seviyelerine katılmak, önerildiği gibi sağlıklı yemek yemek ve yüksek tansiyon, yüksek kolesterol ve diabetes mellitus'un etkili bir şekilde tedavi edilmesi, sağlıklı kiloya ulaşmak ve sürdürmek bireylerin KV sağlık puanını yükseltip kardiyovasküler koruma sağlayacaktır. $O$ zaman sağlığın teşviki ve KVH önleme çabalarımızın erken yaşta ve yaşam boyunca sağlıklı alışkanlıklar olarak kalabilmesi için çocuklar, gençler, genç yetişkinler ve genç ailelere odaklanmak gereklidir. [1]

Bi ve ark. ${ }^{[13]}$ (2015) çalışmalarında Çinli yetişkinlerin çoğunluğunun (\%74.9) KV sağlığının kötü olduğunu göstermektedir. Bu çalışmaya katılan bireylerin LS7'ye göre KV sağlık durumları değerlendirildiğinde \%50.4'ünün ideal, \%34.3'ünün orta, \%15.3'ünün düşük KV sağlık düzeyine sahip olduğu, kadınların KV sağlık düzeyinin erkeklere göre daha yüksek olduğu bulundu ( $p=0.474$ ) (Tablo 5). ÇaIışmaya katılan bireylerin ( $\mathrm{N}=248) \mathrm{LS7}$ puan ortalamasının $8.479 \pm 1.944$ olduğu bulundu. Bu duruma göre bireylerin LS7'ye göre kardiyovasküler sağlık durumlarının yüksek düzeyde olduğu saptandı (Tablo 5).

Yirmi yaş ve üzeri Çinli yetişkinlerde cinsiyete göre KV sağlık 7 bileşeni değerlendirilmiş ve kadınların (\%97.3) sigara içmeme ile ilgili sağlık durumu erkeklere göre (\%43.4) daha yüksek bulunmuştur $(p<0.0001)$. Ayrıca kadınların 


\begin{tabular}{|c|c|c|c|c|c|c|c|c|}
\hline & \multirow[t]{2}{*}{ n (\%) } & \multirow{2}{*}{$\begin{array}{l}\text { Kadın } \\
n=199\end{array}$} & \multirow{2}{*}{$\begin{array}{c}\text { Erkek } \\
n=49\end{array}$} & & \multicolumn{3}{|c|}{ BKI+ } & \\
\hline & & & & & 30 & $25-29.9$ & $18.5-25$ & \\
\hline \multicolumn{9}{|c|}{ LS7 KVS++ } \\
\hline Düşük & 38 (15.3) & 30 & 8 & ${ }^{*} x^{2}=1.493$ & 13 & 5 & 20 & ${ }^{*} x^{2}=54.597$ \\
\hline Orta & $85(34.3)$ & 65 & 20 & $p=0.474$ & 7 & 17 & 61 & $p=0.000$ \\
\hline İdeal & $125(50.4)$ & 104 & 21 & & 2 & 5 & 118 & \\
\hline Ort $\pm S S$ & $8.479 \pm 1.944$ & $8.507 \pm 1.956$ & $8.367 \pm 1.911$ & $\begin{array}{l}t=0.451 \\
p=0.652\end{array}$ & & & & \\
\hline \multicolumn{9}{|c|}{ İyilik Hali ${ }^{++}$} \\
\hline Düşük & $21(8.5)$ & 11 & 10 & $x^{2}=13.490$ & 0 & 1 & 20 & $x^{2}=3.591$ \\
\hline Orta & $69(27.8)$ & 53 & 16 & $p=0.001$ & 6 & 8 & 55 & $p=0.464$ \\
\hline Yüksek & $158(63.7)$ & 135 & 23 & & 16 & 18 & 124 & \\
\hline Ort $\pm S S$ & $40.375 \pm 10.393$ & $41.532 \pm 9.400$ & $35.673 \pm 12.779$ & $\begin{array}{l}t=3.620 \\
p=0.000\end{array}$ & & & & \\
\hline
\end{tabular}

+0-6 puan düşük KVS. 7-8 puan orta KVS. 9-14 puan ideal KVS; ${ }^{++} 8-24$ puan düşük IH. 25-39 puan orta ï. 40-56 puan yüksek iH; *Pearson Chi-Square ${ }^{+}$BKi: Beden Kitle İndeksi kg/m²; Ort \pm SS: Ortalama. Standart sapma; $\mathrm{t}=\mathrm{t}$-testi.

kan basıncı ve AKŞ için ideal KVS ölçüm düzeyleri erkeklerden daha yüksek bulunmuştur ( $p<0.0001)$. ${ }^{[13]}$ Bu çalışmada ise LS7'ye göre kadınların kan basıncı $(p=0.005)$, beden kitle indeksi $(p=0.046)$ ve sigara içme $(p=0.000)$ ile ilgili ideal KV sağlık durumunun erkeklere göre daha yüksek ve anlamlı fark olduğu bulundu (Tablo 3). Kadınların (\%85) ideal KVS fiziksel aktivite düzeyi erkeklerden daha (\%80) yüksek bulunmuştur $(p<0.0001) .{ }^{[13]} \mathrm{Bu}$ çalışmada ise kadınların orta KVS haftalık fiziksel aktivite dakika sayısının erkeklerden daha yüksek bulundu ( $p=0.003$ ) (Tablo 3). Ayrıca İdeal düzeyde fiziksel aktivite dakika sayısı olanların KVS puanla-

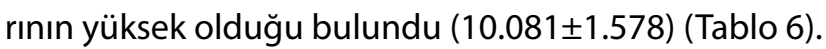

AHA tarafından tanımlanan kalp sağlığı davranışları arasında ideal beslenme en zor olanıdır. İdeal diyetin düşük yüzdesi genel ideal KV sağlığın son derece düşük yüzdesine katkıda bulunmaktadır. Çin'deki sağlıklı diyetle beslenenler genel nüfusun sadece \%1.6'sını oluştururken, bu oran ABD'de erkeklerde \%0.6. kadınlarda \%1.4 olarak gösterilmektedir. ${ }^{[24]}$ Bi ve ark. ${ }^{[13]}$ (2015) çalışmalarında LS7 sağlıklı diyet tercihinde 2-3 seçim yapanların oranı daha yüksek bulunmuş (\%62.3) ve bununla birlikte kadınların (\%1.7) 4-5 seçim yapma oranı erkeklerden (\%1.5) daha fazla bulunmuştur ( $p=0.026$ ). Bizim çalışmada ise her iki cinsiyet arasında LS7 sağlıklı gıda tüketim porsiyon seçimleri arasında anlamlı bir fark bulunmadı ( $p=0.389$ ). Gıda tüketim porsiyon seçimlerinin genel olarak kötü olduğu ve bireylerin çoğunluğunun LS7 sağlıklı diyet tercihinde 0-1 seçim yaptığı ( $n=158, \% 63.7)$ tespit edildi (Tablo 3). Bununla birlikte ayrıca çalışmada bireylerin çoğunluğunun ideal KV sağlık açlık kan şekeri düzeylerinin yüksek olduğu ( $n=150 . \% 60.5)$, ancak cinsiyetler arasında anlamlı fark olmadığı bulundu $(p=0.118)$ (Tablo 3).
İspanya'da ülke çapında yapılan nüfus temelli bir çalışmanın verileri, İspanyol yetişkinlerinin yalnızca \%0.2'sinin ideal KV sağlık durumuna ulaştığını ortaya koymuştur. ${ }^{[25]}$ Bu durum Çin'de yapılan bir çalışmada ise \%0.24 olarak gösterilmiştir. [13] Orta yaşlı Koreli erkeklerde, AHA'nın yedi ideal ölçütünün tamamını elde edenlerin oranı $\% 0.67$ bulunmuştur. ${ }^{[26]}$ İyilik hali, bireylerin sosyal ve doğal çevrede tam fonksiyonel olarak yaşaması için bedenin, zihnin ve ruhun birleştiği optimal sağlık yönelimli bir yaşam biçimi ve iyi olma durumu olarak tanımlamaktadırlar. ${ }^{[27,28]}$ Çalışmamızda bireylerin iyilik halinin yüksek düzeyde $(40.413 \pm 10.397)$ olduğu saptandı (Tablo 5). Ölçekten alınan yüksek puanlar bireyin iyilik hali düzeyinin yüksek olduğunu göstermektedir.[20] Birçok araştırmacı fiziksel olarak aktif olma, sağlıklı ve dengeli beslenmenin KV sağlık için koruyucu olacağında ortak kanıdadır. Bireylerin sağlığı ve iyilik hali ile sürdürmekte olduğu yaşam şekli davranışları birbirini etkilemektedir. İyilik halinin yüksek düzeyde olması bireylerin yaşam şeklinde olumlu değişimler sağlaması açısından önemlidir. Bu nedenle bireylerin iyilik halinin arttırılması için destek ve farkındalık sağlanması ile sağlıklı yaşam şeklini seçmeleri sağlanacaktır. ${ }^{[28]}$

Depresyon ve anksiyete bozuklukları, KV hastalığı olan bireylerde sık görülür ve $\mathrm{KV}$ sağlık sonuçları ile ilişkili olabilir. ${ }^{[29]}$ Bu yaygın psikiyatrik bozukluğu olan bireyler, sağlıklı yaşam şekline uyumda yetersizlik ve sağlıksız yaşam şeklini değiştirmek için motivasyon eksikliği nedeniyle düşük ideal KV sağlık puanlarına sahip olabilirler. ${ }^{[30]}$ Yapılan bir çalışmada daha iyi KV sağlık metrik ölçümleri olan bireylerin daha düşük depresyon riski taşıdığı bulundu. ${ }^{[31]}$ Bu çalışmada ise bireylerin iyilik hallerinin KVS durumlarına etkisinin olmadığını gösterdi (Tablo 5). 


\begin{tabular}{|c|c|c|}
\hline \multicolumn{3}{|l|}{ Haftalık tahmini orta veya yoğun fiziksel aktivite gün sayısı } \\
\hline 1-3 gün/hafta & $8.857 \pm 1.574$ & $40.984 \pm 10.682$ \\
\hline 4 gün ve üzeri /hafta & $10.483 \pm 1.480$ & $40.967 \pm 12.817$ \\
\hline $1-149 \mathrm{dk} / \mathrm{h}$ orta düzey veya $1-74 \mathrm{dk} / \mathrm{h}$ yoğun veya & $8.615 \pm 1.600$ & $40.440 \pm 11.204$ \\
\hline \multicolumn{3}{|l|}{$<60 \mathrm{dk} /$ gün orta veya yoğun aktivite } \\
\hline $\begin{array}{l}\geq 150 \mathrm{dk} / \mathrm{h} \text { orta düzey veya } \geq 75 \mathrm{dk} / \mathrm{h} \text { yoğun aktivite veya } \geq 60 \mathrm{dk} / \text { gün } \\
\text { orta düzey veya yoğun aktivite }\end{array}$ & $10.081 \pm 1.578$ & $40.204 \pm 10.216$ \\
\hline \multicolumn{3}{|l|}{ Gıda tüketim porsiyonu } \\
\hline$\geq 140 / 90$ & $6.500 \pm 0.707$ & $32.500 \pm 33.234$ \\
\hline $120-139 / 80-89$ & $7.846 \pm 1.839$ & $39.666 \pm 9.874$ \\
\hline$<120 / 80$ & $9.029 \pm 1.868$ & $41.149 \pm 10.443$ \\
\hline \multicolumn{3}{|l|}{ Beden Kitle İndeksi } \\
\hline $30 \mathrm{~kg} / \mathrm{m}^{2}$ & $6.636 \pm 1.963$ & $44.454 \pm 8.571$ \\
\hline $25-29.9 \mathrm{~kg} / \mathrm{m}^{2}$ & $7.825 \pm 1.583$ & $42.650 \pm 9.406$ \\
\hline $18.5-25 \mathrm{~kg} / \mathrm{m}^{2}$ & $8.715 \pm 1.932$ & $39.729 \pm 10.606$ \\
\hline \multicolumn{3}{|l|}{ Açlık Kan Şekeri } \\
\hline$\geq 126 \mathrm{mg} / \mathrm{dL}$ & $5.666 \pm 1.527$ & $43.000 \pm 10.583$ \\
\hline $100-125 \mathrm{mg} / \mathrm{dL}$ & $7.505 \pm 1.901$ & $40.084 \pm 9.801$ \\
\hline
\end{tabular}

*Ort \pm SS: Ortalama. Standart sapma; SS.

İdeal beslenme, fiziksel olarak aktif olma ve sigara içmemek de dahil olmak üzere KV sağlık davranışları, depresyona girme intimalinin azalmasıyla ilişkilidir. ${ }^{[31,32]}$ Yapılan bir çalışmada ideal diyet alımının düşük depresyon prevalansı ile ilişkili olduğu belirtilmiştir. ${ }^{[31]}$ Gaye ve ark. ${ }^{[33]}$ (2016)'nın yaptığı çalışmada erkeklere kıyasla kadınlarda orta ve ideal yaşam şekli KV sağlık prevalansının, depresif belirtilerden bağımsız olarak daha yüksek olduğu bulunmuştur. Li ve ark $(2015)^{[31]}$ erkeklerde olan depresif semptomların yüksek ideal KV sağlık oranlarını düşürdüğünü belirtmiştir. Bu çaIışmada ideal KV sağlık için sağlıklı diyet tercihinde 4-5 seçim yapanların, ideal KB, AKŞ düzeyi olanların ve asla sigara içmeyenlerin iyilik halinin yüksek düzeyde olduğu bulundu (Tablo 6). Ayrıca BKi $30 \mathrm{~kg} / \mathrm{m}^{2}$ olan bireylerin düşük düzeyde iyilik haline sahip olduğu belirlendi (Tablo 6). BKi normal düzeyde olan bireylerin yüksek iyilik haline sahip oldukları tespit edildi (Tablo 5). Bununla birlikte çalışmada KV sağlık için 0-1 diyet seçimi yapanların oranının çoğunluğu (\%63.7) teşkil etmesinden dolayı, bu bireylerin iyilik halinin düşük düzeyde (39.879 \$10.577) olduğu görülmektedir (Tablo 3, 6). Yapılan bir çalışmada fiziksel egzersiz yapan üniversite öğrencilerinin iyilik halinin daha yüksek olduğu saptanmıştır. Aynı çalışmada alkol ve sigara kullanıp kullanmama değişkenlerine göre öğrencilerin iyilik hali düzeylerinde anlamlı fark bulunmamıştır. ${ }^{[34]}$ Çalışmada haftada 1-3 gün fiziksel aktivite (orta düzey KVS) yapan bireylerin iyilik hali düzeylerinin yüksek olduğu bulundu (Tablo 6).

\section{Sonuç}

Sonuç olarak, çalışmaya katılan bireylerin yarısının ideal KVS düzeyine sahip olduğu, bireylerin KVS durumu puan ortalamalarının yüksek düzeyde olduğu bulundu. Çalışmada kan basıncı, beden kitle indeksi ve sigara içme durumu ile ilgili kadınların ideal KVS durumu puanının erkeklerin- 
kinden anlamlı olarak daha yüksek olduğu, kadınların orta KVS haftalık fiziksel aktivite dakika sayısının erkeklerden daha yüksek olduğu bulundu. Ayrıca ideal düzeyde fiziksel aktivite dakika sayısı olanların KVS puanlarının yüksek olduğu saptandı.

Bireylerin iyilik halinin yüksek düzeyde olduğu, kadınların erkeklere göre daha yüksek düzeyde iyilik haline sahip olduğu bulundu. Bireylerin iyilik halinin KVS üzerine etkisini açıklamak için anlamlı düzeyde olmadığı bulundu.

Sağlıklı davranışların teşvik edilmesi tüm nüfus düzeyinde uygulandığında daha etkilidir. Kitle iletişim araçları ile sağlık eğitimi, KV hastalıkların önlenmesi, tütün kontrol yasaları ve düzenlemelerinin geliştirilmesi ve yüksek sodyum ve yüksek yağ tüketimini kısıtlayan gıda politikalarının teşvik edilmesinin yanı sıra, fiziksel aktiviteyi destekleyici sağlık kuruşlarına erişimin iyileştirilmesi konusunda halkın bilinçlendirilmesi kampanyaları, bireylerin KV risk faktörlerinin değiştirilmesi ve kontrol altında tutulmasında önemli olabilir. Ayrıca, yüksek riskli bireyler arasında hipertansiyon, hiperkolesterolemi ve diyabet gibi KV risk faktörlerinin tedavisinin ve kontrolünün, klinik KV hastalıkların önlenmesinde de etkili olduğu gösterilmiştir. ${ }^{[13]}$

\section{Teşekkür}

Çalışmamıza katılarak desteklerini ve işbirliğini esirgemeyen değerli katılımcılarımıza teşekkür ederiz.

Etik Kurul Onayı: İstanbul Üniversitesi Diş Hekimliği Fakültesi Klinik Araştırmalar Etik Kurulu. (Numara: 1235/Tarih:10.04.2019).

Hakem Değerlendirmesi: Dış bağımsız.

Çıkar Çatışması: Yazarlar arasında herhangi bir çıkar çatışması bulunmamaktadır.

Yazarlık Katkıları: Konsept: H.U., Dizayn: H.U., H.B.O., Veri Toplama ve İşleme: H.U., H.B.O., Analiz veya Yorumlama: H.U., Literatür arama: H.U., H.B.O., Yazan: H.U.

\section{Kaynaklar}

1. Sanchez E. Life's Simple 7= Vital But Not Easy. Editorial. J Am Heart Assoc 2018;7:1-4.

2. Kıngır $S$, Şengün Hi, Karakaş $A$, Çemberlitaş I. Determining The Reasons of University Students' Fast Food Preferences: Dicle University Case. [Article in Turkish]. Journal of Travel and Hospitality Management 2015;12:102-19.

3. Stojisavljevic' D, Jankovic' J, Eric' M, Marinkovic' J, Jankovic S. Cardiovascular Health Status and Metabolic Syndrome in Adults Living in a Transition European Country: Findings from a Population-Based Study. J Stroke Cerebrovascular Dis 2018;27:568-74.

4. Arts J, Fernandez ML, Lofgen IE. Coronary heart disease risk factors in college students. Adv Nutr 2014;5:177-87.

5. Estrella ML, Rosenberg NI, Durazo-Arvizu RA, Gonzalez HM,
Loop MS, Singer RH. et al. The association of employment status with ideal cardiovascular health factors and behaviors among Hispanic/Latino adults: Findings from the Hispanic Community Health Study/Study of Latinos (HCHS/SOL). PLoS One 2018;13:e027652.

6. Guo L, Zhang S. Association between ideal cardiovascular health metrics and risk of cardiovascular events or mortality: A meta-analysis of prospective studies. Clin Cardiol 2017;40:1339-46.

7. Vu TH, Lloyd-Jones DM, Liu K, Stamler J, Garside DB, Daviglus ML. Optimal Levels of All Major Cardiovascular Risk Factors in Younger Age and Functional Disability in Older Age: The Chicago Heart Association Detection Project in Industry 32Year Follow-Up Health Survey. Circ Cardiovasc Qual Outcomes 2016;9:355-63.

8. Yang Q, Cogswell ME, Flanders WD, Hong Y, Zhang Z, Loustalot $\mathrm{F}$, et al. Trends in cardiovascular health metrics and associations with all-cause and CVD mortality among US adults. JAMA 2012;307:1273-83.

9. Ford ES, Greenlund KJ, Hong Y. Ideal cardiovascular health and mortality from all causes and diseases of the circulatory system among adults in the United States. Circulation 2012;125:987-95.

10. Ommerborn MJ, Blackshear CT, Hickson DA, Griswold ME, Kwatra J, Djoussé L, et al. Ideal Cardiovascular Health and Incident Cardiovascular Events: The Jackson Heart Study. Am J Prev Med 2016;51:502-6.

11. Saleem Y, DeFina LF, Radford NB, Willis BL, Barlow CE, Gibbons LW. et al. Association of a favorable cardiovascular health profile with the presence of coronary artery calcification. Circ Cardiovasc Imaging 2015;8:e001851.

12. Shay CM, Ning $H$, Allen NB, Carnethon MR, Chiuve SE, Greenlund KJ, et al. Status of cardiovascular health in US adults: prevalence estimates from the National Health and Nutrition Examination Surveys (NHANES) 2003-2008. Circulation 2012;125:45-56.

13. Bi Y, Jiang $Y$, He J, Xu Y, Wang $L, X u M$, et al. Status of cardiovascular health in Chinese adults. J Am Coll Cardiol 2015;65:101325.

14. Djoussé L, Petrone AB, Blackshear C, Griswold M, Harman JL, Clark CR, et al. Prevalence and changes over time of ideal cardiovascular health metrics among African-Americans: the Jackson Heart Study. Prev Med 2015;74:111-6.

15. Janković S, Stojisavljević D, Janković J, Erić M, Marinković J. Status of cardiovascular health in a transition European country: findings from a population-based cross-sectional study. Int $J$ Public Health 2014;59:769-78.

16. Karakoç Kumsar A, Taşkın Yılmaz F. Kardiyovasküler Hastalıklar Risk Faktörlerinden Korunmada Hemşirenin Rolü Online Türk Sağlık Bilimleri Dergisi 2017;2:18-27.

17. Zhao Y, Yan H, Yang R, Li Q, Dang S, Liu R, et al. Status of cardiovascular health among adults in a rural area of Northwest China: Results from a cross-sectional study. Medicine (Baltimore) 2016;95:e4245. 
18. Thacker EL, Gillett SR, Wadley VG, Unverzagt FW, Judd SE, McClure LA ,et al. The American Heart Association Life's Simple 7 and Incident Cognitive İmpairment=The Reasons for Geographic and Racial Differences in Stroke (Regards) Study. J Am Heart Assoc 2014;3:e000635.

19. Diener E, Wirtz D, Tov W, Kim-Prieto C, Choi D-won, Oishi S, et al. New Well-Being Measures: Short Scales to Assess Flourishing and Positive and Negative Feelings. Soc Indic Res 2010;97:143-56

20. Fidan M. Usta F. İyilik Hali Ölçeğinin Türkçe Formunun Güvenirlik Ve Geçerliğinin İncelenmesi. Eğitim ve Öğretim Araştırmaları Dergisi 2013;2:265-69.

21. Lloyd-Jones DM, Hong Y, Labarthe D, Mozaffarian D, Appel LJ, Van Horn L, et al. Defining and setting national goals for cardiovascular health promotion and disease reduction: the American heart association's strategic impact goal through 2020 and beyond. Circulation 2010;121: 586-613.

22. Fang N, Jiang M, Fan Y. Ideal cardiovascular health metrics and risk of cardiovascular disease or mortality: a meta-analysis. Int. J Cardiol 2016;214:279-83.

23. Guo L. Zhang S. Association between ideal cardiovascular healthmetrics and risk of cardiovascular events or mortality: a meta-analysis of prospective studies. Clin Cardiol 2017;1-8.

24. Huffman MD, Capewell S, Ning H, Shay CM, Ford ES, Lloyd-Jones DM. Cardiovascular health behavior and health factor changes (1988-2008) and projections to 2020: results from the National Health and Nutrition Examination Surveys. Circulation 2012;125:2595-602.

25. Graciani A, León-Muñoz LM, Guallar-Castillón P, Rodríguez-Artalejo F, Banegas JR, Cardiovascular health in a southern Mediterranean European country: a nationwide population-based study. Circ Cardiovasc Qual Outcomes 2013;6:90-8.

26. Kim JY, Ko YJ, Rhee CW, Park BJ, Kim DH, Bae JM, et al. Cardiovascular health metrics and all-cause and cardiovascular disease mortality among middle-aged men in Korea: the Seoul male cohort study. J Prev Med Public Health 2013;46:319-28.

27. Myers JE. Sweeney TJ. Witmer JM. The Wheel of welness counselling for wellness $=$ a holistic model for treatment planning. Journal of Counseling and Development 2000;78:251-66.

28. Doğan T. Üniversite Öğrencilerinin iyilik halinin "maneviyat" ve "serbest zaman" boyutlarının incelenmesi. Türk Psikolojik Danışma ve Rehberlik Dergisi 2006;26:1-16.

29. Cohen BE, Edmondson D, Kronish IM. State of the art review: depression. stress. anxiety. and cardiovascular disease. Am J Hypertens 2015;28:1295-302.

30. Szlejf C, Suemoto CK, Santos IS, Brunoni AR, Nunes MA, Viana $M C$, et al. Poorer Cardiovascular Health is associated with psychiatric comorbidity: results from the ELSA-Brasil Study. Int J Cardiol 2019;274:358-65.

31. Li Z, Yang X, Wang A, Qiu J, Wang W, Song Q, et al. Association between Ideal Cardiovascular Health Metrics and Depression in Chinese Population: A Cross-sectional Study. Sci Rep 2015:5;11564.

32. Seppala J, Kauppinen A, Kautiainen $H$, Vanhala M, Koponen $H$. Depression and diet. Duodecim 2014;130:902-9.

33. Gaye B, Prugger C, Perier MC, Thomas F, Plichart M, Guibout C, et al. High level of depressive symptoms as a barrier to reach an ideal cardiovascular health. The Paris Prospective Study III. Sci Rep 2016;6:1-10.

34. Doğan T. Üniversite öğrencilerinin iyilik halinin incelenmesi. H.Ü. Eğitim Fakültesi Dergisi 2006;3:120-29. 